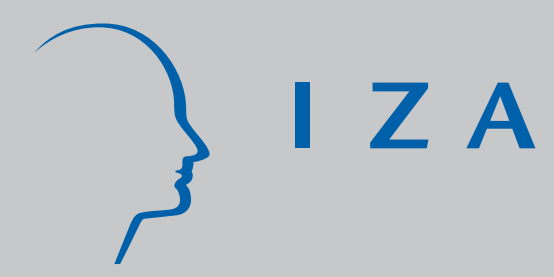

IZA DP No. 3883

How Opportunity Costs Decrease the Probability

of War in an Incomplete Information Game

Solomon Polachek

J un Xiang

December 2008 


\title{
How Opportunity Costs Decrease the Probability of War in an Incomplete Information Game
}

\author{
Solomon Polachek \\ State University of New York at Binghamton \\ and IZA \\ Jun Xiang \\ University of Rochester
}

\section{Discussion Paper No. 3883 \\ December 2008}

\author{
IZA \\ P.O. Box 7240 \\ 53072 Bonn \\ Germany \\ Phone: +49-228-3894-0 \\ Fax: +49-228-3894-180 \\ E-mail: iza@iza.org
}

\begin{abstract}
Any opinions expressed here are those of the author(s) and not those of IZA. Research published in this series may include views on policy, but the institute itself takes no institutional policy positions.

The Institute for the Study of Labor (IZA) in Bonn is a local and virtual international research center and a place of communication between science, politics and business. IZA is an independent nonprofit organization supported by Deutsche Post World Net. The center is associated with the University of Bonn and offers a stimulating research environment through its international network, workshops and conferences, data service, project support, research visits and doctoral program. IZA engages in (i) original and internationally competitive research in all fields of labor economics, (ii) development of policy concepts, and (iii) dissemination of research results and concepts to the interested public.
\end{abstract}

IZA Discussion Papers often represent preliminary work and are circulated to encourage discussion. Citation of such a paper should account for its provisional character. A revised version may be available directly from the author. 
IZA Discussion Paper No. 3883

December 2008

\section{ABSTRACT \\ How Opportunity Costs Decrease the Probability of War in an Incomplete Information Game}

This paper shows that the opportunity costs resulting from economic interdependence decrease the equilibrium probability of war in an incomplete information game. This result is strongly consistent with existing empirical analyses of the inverse trade-conflict relationship, but is the opposite of the conclusion reached by Gartzke et al. (2001), who reject the opportunity cost argument in a game-theoretic framework. As a result of this paper's findings, one cannot dismiss the opportunity cost argument as the explanation why trading nations fight less. Instead this study reaffirms the central position of opportunity costs as the basis for the inverse trade-conflict relationship, thus implying that one need not rely on signaling.

JEL Classification: F10, C7, P16

Keywords: war, conflict, trade, trade-conflict relationship, interdependence, incomplete information game, signaling

Corresponding author:

Solomon Polachek

LT 1015

Binghamton University

P.O. Box 6000

Binghamton, New York 13902

USA

E-mail:polachek@binghamton.edu 


\section{Introduction}

Data strongly indicate an inverse relationship between conflict and trade: Country pairs exhibiting the most trade engage in the least bilateral conflict. One (indeed the predominant) reason for this inverse trade-conflict relationship is opportunity costs. Opportunity costs arise because nations tend to forgo trade with combatants especially when a war erupts. As such, dyadic conflict leads to a diminution of bilateral trade which results in lost gains from trade for both nations. To prevent these potential gains from trade losses, trading nations become more cooperative, thereby decreasing the hostility they exhibit between each other. This explanation is know as the "opportunity cost" argument.

A recent influential article (Gartzke et al., 2001) claims that the opportunity cost argument is incorrect, stating "opportunity costs ... cannot deter disputes." Instead Gartzke et al. argue scholars observe an inverse conflict-trade relation because of "costly signaling." In Gartzke et al.'s model a trading nation signals resolve "without resorting to military violence" by threatening to cut off trade, and as a result this signal leads to less high-level conflict and more overall cooperation. Gartzke et al. (2001) reach this conclusion in two steps. First, within the context of an incomplete information game, they (erroneously) claim that gains from trade do not lead to a reduced probability of war. Second, they show that gains from trade do reduce the probability of war in a game-theoretic "signaling" model. From this they conclude signaling is the "true" underlying mechanism through which gains from trade operate in reducing bilateral conflict.

We argue in this paper that Gartzke et al. (2001) are incorrect in dismissing the opportunity cost model. First, we show they are mistaken in claiming that trade gains fail to reduce conflict in an incomplete information game. As will be illustrated, they simply err in their mathematical proof. Second, we argue that without potential gains from trade losses, their signaling model would not yield an inverse trade-conflict relationship. This means even their signaling model relies on potential trade losses associated with conflict. From this we conclude that the opportunity costs of potentially lost gains from trade are indeed 
the important reason why scholars predominantly observe dyads to be more cooperative the more they trade with each other. Our result is consistent with Polachek (1980) who derives the inverse conflict-trade relationship using a microeconomic model, as well as with Martin, Mayer, and Thoenig (forthcoming) who derive the inverse conflict-trade relationship based on a more general mechanism design game. Our results are significant because they get at the underlying political reason why trade helps deter conflict.

\section{$2 \quad$ Literature Review}

To date a large body of empirical research studies whether trade has a pacifying effect on international conflict, or not. By employing various data samples, a number of regression specifications, and several measures of interdependence, the preponderance of this research finds a pacifying effect. ${ }^{1}$ In addition, in recent years, as foreign direct investment (FDI)'s growth exceeded that of international trade, a number of studies began to examine the effect of FDI on international conflict (e.g., Gasiorowski 1986; Gartzke et al. 2001; Polachek et al. 2007). These studies show empirically that, as with trade, FDI has a pacifying effect on conflict, implying that FDI has become an important economic force mitigating international conflict. This second strand of literature, therefore, has increased the scope of economic interdependence, making it even more important to understand the underlying reasons for the inverse relationship between interdependence (e.g., trade and FDI) and conflict.

Despite the abundance of this empirical literature, little attention has been paid to the underlying formal models behind why economic interdependence lessens dyadic conflict. However, formulating how economic interdependence affects international conflict is a critical step toward better understanding this important phenomenon. Commenting on the relationship between interdependence and conflict, Mansfield and Pollins (2001) write

\footnotetext{
${ }^{1}$ Barbieri (1996), however, shows that trade increases the probability of conflict. Many follow-up studies have argued her results are not robust: trade shows a pacifying effect on international conflict once more appropriate model specifications are introduced (e.g., Oneal and Russett, 1999; Xiang et al., 2007).
} 
"First, there is a need to improve the theoretical basis of claims about the influence of interdependence on conflict and to specify more clearly the causal mechanisms underlying any such relationship" (p. 834).

Early models were complete information games which led to an opportunity cost argument. This means that nations protect gains from trade by avoiding belligerence and maintaining peace. Other studies question this approach. For example, Morrow (1999) argues that the relationship between trade and war is ambiguous. He argues that trade affects conflict not because of opportunity costs, but because trade signals resolve. Building on this concept, Gartzke et al. (2001) likewise employ a signaling game in which economic interdependence serves as a costly signal to demonstrate a state's resolve in an incomplete information world. Their two-player game is as follows. First, state B decides whether or not to retain interdependence. After observing B's decision, state A makes an offer/demand. Finally, B either accepts it, leading to peace, or rejects it, leading to war. It is an incomplete information game in the sense that A does not know B's resolve (e.g., costs of fighting). In the separating equilibrium of this game, resolved states (e.g., states with low war costs) are willing to destroy interdependence at the onset whereas unresolved states (e.g., high war costs states) retain it, thus signaling their respective resolves.

In that same research Gartzke et al. (2001) also attempt to demonstrate the widely cited opportunity costs argument, namely that the benefits of interdependence deter conflict, fails to work in a game theoretical framework. They argue the equilibrium probability of war is independent of the opportunity costs associated with interdependence. They claim that since state $\mathrm{A}$ is aware of the benefit arising from interdependence with state $\mathrm{B}$, it will adjust its offer to B to subsume this benefit. ${ }^{2}$ And as a result of that, they argue, the equilibrium probability for B to reject the offer (i.e., the equilibrium probability of war) should remain the same.

\footnotetext{
${ }^{2}$ The intermediate step of reasoning is as follows: state B will accept A's offer as long as the associated payoff is no less than the expected payoff of fight. B receives additional benefits in the case of economic interdependence but its expected payoff of fight remains the same. As a result, A can subtract the benefit of interdependence from its offer and make B still accept the offer.
} 
Their proposition on the effect of opportunity costs is incomplete, however. Since a game involves strategic interactions of both sides, they neglect the effect on the proposing state (i.e., state A). The benefit from interdependence to the proposer increases its payoff in the case of peace, which also impacts the size of the optimal offer. Therefore, it is not true "opportunity costs generally do not alter the prospects of engaging in costly contests" (p. 400). Indeed, we find opportunity costs arising from economic interdependence can either deter war or reduce the equilibrium probability of war in an incomplete information model like the one examined by Gartzke et al. (2001).

\section{The Model}

\subsection{The Basic Setup}

In this section, we present a simple crisis bargaining game and show the existence of opportunity costs associated with economic interdependence induces lower equilibrium probability of war. We illustrate this effect of economic interdependence by comparing the equilibrium probabilities of war in two variants of the model - one without economic interdependence and the other with economic interdependence.

The presented crisis bargaining game is called ultimatum game and it is described as follows. In this game, two players - state $\mathrm{A}$ and state $\mathrm{B}$ - divide a pie valued at $W$ (e.g., a piece of territory). State A takes the first move and makes a take-it-or-leave-it offer $s$. Then state B decides whether or not to accept it. The rejection of the offer leads to war and the acceptance leads to a peaceful settlement as indicated by $s$. The expected payoffs associated with each outcome are the following. Assume the winning state obtains $W$ and the losing side gets nothing. Let war costs be $c_{1}$ for state $\mathrm{A}$ and $c_{2}$ for state $\mathrm{B}$. Further, assume A wins with probability $p$. Therefore, in the case of war, the expected payoffs are $p W-c_{1}$ and $(1-p) W-c_{2}$ for $\mathrm{A}$ and $\mathrm{B}$ respectively. In the case of a peaceful settlement, the resulting payoff is $W-s$ for state A and $s$ for state $\mathrm{B}$. 
In the case everything is public information, in equilibrium state A will offer $s^{*}=$ $(1-p) W-c_{2}$ and state $\mathrm{B}$ will accept it, assuming $\mathrm{B}$ will always accept the offer when it is indifferent. In this peaceful settlement, $\mathrm{A}$ gets $p W+c_{2}$ and $\mathrm{B}$ gets $(1-p) W-c_{2}$. To get more interesting cases in which war occurs with positive probabilities, we introduce some uncertainty into this game. The critical assumption is that each state knows its own war costs but only knows the other side's costs are drawn from certain probability distribution. Following Gartzke et al., $c_{1}$ and $c_{2}$ are both drawn from a uniform distribution on the $[0,1]$ interval. With this incomplete information on war costs, we show in the following the equilibrium probability of war is smaller in the case when economic interdependence exists.

\subsection{Case I: Without Economic Interdependence}

First, we examine the case with no economic interdependence. To solve this game, we use the concept of perfect Bayesian equilibrium (PBE) - it requires specifying equilibrium strategies and beliefs for both states. This game can be solved by backward induction. In the first step, we find the equilibrium strategy for state B. This is relatively easy given B makes the final move - B will accept the offer as long as its share of the pie is no less than its expected payoff of war. Mathematically, B's best response is

$$
\begin{aligned}
& \text { Accept } \Longleftrightarrow c_{2} \geq(1-p) W-s \\
& \text { Reject } \Longleftrightarrow c_{2}<(1-p) W-s .
\end{aligned}
$$

Note all the parameters in above inequalities are known to state B so no uncertainty is involved at this stage of decision.

As the second step, given B's best response at the last move, we find A's best response. Since state A does not observe B's type (i.e., $c_{2}$ ), A's optimal strategy is to make an offer of $s$ that maximizes its expected payoff given B's best response and A's belief of B's type. 
In mathematical terms, this means A chooses $s$ to maximize the following expected utility

$$
\operatorname{Eu}_{1}(s \geq 0)=(W-s) \operatorname{Pr}\left(c_{2} \geq(1-p) W-s\right)+\left(p W-c_{1}\right) \operatorname{Pr}\left(c_{2}<(1-p) W-s\right) .
$$

Solve above maximization problem we find $s^{*}-$ the optimal $\mathrm{s}-$ as follows:

$$
s^{*}=\frac{-1+2(1-p) W+c_{1}}{2}
$$

The first important result is summarized in proposition 1.1.

Proposition 1.1. There is a unique PBE to this game. In the equilibrium, the strategy of state $A$ is to make an offer $s^{*}=\frac{-1+2(1-p) W+c_{1}}{2}$ and its belief about $B$ 's type is $\mu_{c_{2}}=1$. The strategy of state $B$ is to accept $s^{*}$ if $c_{2} \geq(1-p) W-s^{*}$ and to reject it if $c_{2}<(1-p) W-s^{*}{ }^{3}$

Since our main research interest is to compare the equilibrium probability of war, proposition 1.2 specifies this probability for the case without economic interdependence, which is given by the equilibrium probability of rejection of $s^{*}$ by state B. Mathematically, it is

$$
\begin{aligned}
\operatorname{Pr}(\text { war }) & =\operatorname{Pr}\left(\mathrm{B} \text { rejects } s^{*}\right) \\
& =\operatorname{Pr}\left(c_{2}<(1-p) W-s^{*}\right) \\
& =\frac{1-c_{1}}{2} .
\end{aligned}
$$

Proposition 1.2. The equilibrium probability of war for the case with no economic interdependence is $\frac{1-c_{1}}{2}$.

As is evident, this probability is solely determined by $c_{1}$ - state A's type - and it is positive. ${ }^{4}$ Next, we want to show this equilibrium probability of war is reduced with the addition of economic interdependence into the model.

\footnotetext{
${ }^{3}$ Here we do not consider possible mixed strategies which exist in the case $c_{2}=(1-p) W-s^{*}$.

${ }^{4}$ This is because we have a zero probability to have $c_{1}=1$, given $c_{1}$ is drawn from a continuous distribution.
} 


\subsection{Case II: With Economic Interdependence}

When economic interdependence exists between states A and B before the crisis bargaining, each state receives a positive welfare in addition to its share of the pie were there to be a peaceful settlement. On the other hand, in the case of war, economic interdependence will be eradicated, thereby capturing the opportunity costs of lost trade when war results. This is the key assumption employed in the model to test the opportunity cost argument. Let $b_{1}>0$ and $b_{2}>0$ denote the benefit from interdependence for states $\mathrm{A}$ and $\mathrm{B}$, respectively. ${ }^{5}$ Assume values of $b_{1}$ and $b_{2}$ are known to both states. The resulting change is reflected in the payoffs for the peaceful settlement outcome - in this case state A receives $W-s+b_{1}$ and state B receives $s+b_{2}$ instead. Once again, we solve this variant of game via backward induction. First, the best response for B is

$$
\begin{aligned}
& \text { Accept } \Longleftrightarrow c_{2} \geq(1-p) W-s-b_{2} \\
& \text { Reject } \Longleftrightarrow c_{2}<(1-p) W-s-b_{2} .
\end{aligned}
$$

Next, given B's best response and A's belief about B's type, A offers $s$ which maximizes the following equation

$\operatorname{Eu}_{1}(s \geq 0)=\left(W-s+b_{1}\right) \operatorname{Pr}\left(c_{2} \geq(1-p) W-s-b_{2}\right)+\left(p W-c_{1}\right) \operatorname{Pr}\left(c_{2}<(1-p) W-s-b_{2}\right)$.

When solving this maximization problem we get the optimal $s$ to be ${ }^{6}$

$$
s^{*}=\frac{-1+2(1-p) W+c_{1}+b_{1}-b_{2}}{2} .
$$

The equilibrium result for the case with economic interdependence is summarized in proposition 2.1 .

\footnotetext{
${ }^{5}$ We do not assume $b_{1}$ and $b_{2}$ to be necessarily equal to incorporate the notion that states can bargain along the contract curve.

${ }^{6}$ We need certain restriction on the parameters values to obtain the following equilibrium strategy.
} 
Proposition 2.1. There is a unique PBE to this game, and the equilibrium is comprised of two parts. If $1-c_{1}-b_{1}-b_{2} \geq 0$, A's strategy is to make an offer $s^{*}=\frac{-1+2(1-p) W+c_{1}+b_{1}-b_{2}}{2}$ and its belief about B's type is $\mu_{c_{2}}=1$; B's strategy is to accept $s^{*}$ if $c_{2} \geq(1-p) W-s^{*}-b_{2}$ and to reject it if $c_{2}<(1-p) W-s^{*}-b_{2}$. If $1-c_{1}-b_{1}-b_{2}<0$ (so a corner solution exists in this case), A's strategy is to make an offer $s^{*}=(1-p) W-b_{2}$ and its belief about $B$ 's type is $\mu_{c_{2}}=1 ; B$ always accepts $s^{*}$ in equilibrium.

The critical observation from proposition 2.1 is that, with economic interdependence, state A adjusts its offer by the amount of $\frac{b_{1}-b_{2}}{2}$. This result suggests that A will increase its offer to B should $b_{1}$ dominates $b_{2}$, which is the opposite of what is predicted by Gartzke et al. Even in the extreme case where $b_{1}$ is close to zero - this corresponds to a situation in which only state B benefits from economic interdependence - state A only cuts its offer by half of $b_{2}$. Thus, even when incorporating economic interdependence, in no event will state A cut its offer to B by the amount of $b_{2}$ as suggested by Gartzke et al. (2001). We will discuss an intuitive explanation of this finding after the presentation of next equilibrium result.

The probability of war in equilibrium - our quantity of interest - is calculated as before, ${ }^{7}$

$$
\begin{aligned}
\operatorname{Pr}(\text { war }) & =\operatorname{Pr}\left(\mathrm{B} \text { reject } s^{*}\right) \\
& =\operatorname{Pr}\left(c_{2}<(1-p) W-s^{*}-b_{2}\right) \\
& =\frac{1-c_{1}-b_{1}-b_{2}}{2} .
\end{aligned}
$$

Proposition 2.2. If $1-c_{1}-b_{1}-b_{2} \geq 0$, the equilibrium probability of war is $\frac{1-c_{1}-b_{1}-b_{2}}{2}$. If $1-c_{1}-b_{1}-b_{2}<0$, the equilibrium probability of war is 0 .

Proposition 2.2 shows the most important result of this study: the equilibrium probability of war is lower with economic interdependence - it is reduced from $\frac{1-c_{1}}{2}$ to $\frac{1-c_{1}-b_{1}-b_{2}}{2} .8$

\footnotetext{
${ }^{7}$ This probability becomes zero when certain restriction applies.

${ }^{8}$ Recall that $b_{1}$ and $b_{2}$ are both positive.
} 
In the extreme case - given $\left(1-c_{1}-b_{1}-b_{2}<0\right)$ is satisfied - a peaceful settlement will be assured. This mathematical result clearly bears out the opportunity costs argument: compared to their counterparts interdependent states are less likely to fight due to the fear of losing economic benefits. This is in contrast to Gartzke et al's claim that the probability of war remains the same with economic interdependence.

In addition, proposition 2.2 suggests that the probability of war is negatively correlated with the economic benefit for each interdependent state $-b_{1}$ and $b_{2}$. This theoretical result is very consistent with the empirical findings that dyadic trade, which is used to approximate benefits of trade for each state, is negatively related to the probability of war. Therefore, proposition 2.2 provides a theoretical foundation for existing empirical research on trade and conflict, and at the same time it is buttressed by existing empirical evidence.

The discussion thus far has focused on showing the technical details. Next, we offer an intuitive explanation. Recall Gartzke et al.'s numerical example (pages 398-400 of their paper): The pie to be divided (W) is $\$ 100$ and the incomplete information offer to $B$ is $s$ (which in their notation is denoted as $d$ ). As such, war is avoided if $B$ receives $s$, and $A$ keeps $(\$ 100-s)$. In the case $B$ rejects $s$, each state pays $\$ 20$ for fighting and wins with an equal probability. Given war costs for $B$ are uniformly distributed between 0 and 40, Gartzke et al. incorrectly calculated $s^{*}=30$. Our equilibrium solution gives $s^{*}=40$. Their answer is incorrect because the expected payoff for $A$ is 50 when $s^{*}=30$ and is 52.5 when $s^{*}=40 .{ }^{9}$ The latter case is an apparent profit gain for $A$. Next, they suppose interdependence. They "assume that interdependent dyads are those that derive some benefit from economic linkage" (p 400), which they assume to be $\$ 10$ for each nation. Because "not fighting is more beneficial in interdependent dyads, and $B$ should more often prefer $A$ 's" offer rather than fight, they mistakenly claim "A simply demands commensurately more" leading $A$ to offer $(s=\$ 100-(s-\$ 10))$, which neglects $A$ 's own incentive to induce its opponent not to fight. With economic interdependence, $A$ offers $s^{*}=40$, which gives $A$ a higher

\footnotetext{
${ }^{9}$ To calculate $A$ 's expected payoff, simply use $\left(100-s^{*}\right) \operatorname{Pr}\left(c_{2} \geq 50-s^{*}\right)+30 \operatorname{Pr}\left(c_{2}<50-s^{*}\right)$.
} 
expected payoff than $s^{*}=20{ }^{10}$ In short, Gartzke et al. erroneously fixed the equilibrium probability at 0.5 and accordingly adjusted $A$ 's optimal offer. As such they have violated the expected utility calculation and have turned the incomplete information game into a complete information game.

\section{Discussion}

The formal models in the last section show that benefits from economic interdependence (i.e., $b_{i}$ ) explain the reduced probability of war in equilibrium. In other words, our finding means economic interdependence - more precisely, the benefit from economic interdependencedeters international conflict, which buttresses the traditional opportunity cost argument of trade. This result is important for two reasons. First, it shows the opportunity cost argument is valid in a game-theoretical framework, which is in contrast to the claim by Gartzke et al (2001). Therefore, the opportunity cost argument can explain why economic interdependence decreases the probability of war. Second, it provides a theoretical foundation for the empirical result that trade has a pacifying effect on conflict, and as a result implies that it is not necessary to resort to the costly signaling argument to explain why trade deters conflict.

The discussion thus far treats the two mechanisms (i.e., incomplete information and costly signaling) as if they build upon very different assumptions and employ distinctive approaches. A closer scrutiny shows some commonality underlies both mechanisms, namely the concept of opportunity costs is critical for both mechanisms to work. This is clearly the case for the opportunity cost argument, which essentially emphasizes how the economic dimension (i.e., opportunity costs) affects the political dimension (i.e., foreign policies). For the costly signaling proposition, opportunity costs also comprises an essential part of the argument. To see this, first consider Spence's (1973) original work which first proposes the costly signaling argument (albeit in the labor market rather than in a political setting).

\footnotetext{
${ }^{10}$ The expected payoffs are 70 and 60 , respectively.
} 
Here ability is unobserved, but potential employees can signal their respective abilities to employers through acquiring different levels of education. In equilibrium high ability workers obtain more education than low ability workers. The model's critical underlying assumption is more able workers are willing to purchase costly education by forgoing wages when they are young (opportunity costs) to signal their high productivity. In Gartzke et al.'s costly signaling model, resolved states signal their willingness to fight by threatening to pass the costs of cutting off trade, thereby forgoing gains from trade. Unresolved states who are unwilling to fight do not forgo the benefits of trade, thereby retaining their economic interdependence. The key assumption in this case is that the loss of interdependence is costly (i.e., opportunity costs) and that the action to retain interdependence is negatively correlated with state resolve. This discussion shows the existence of opportunity costs is indispensable, which suggests Gartzke et al.'s costly signaling model builds upon the old concept - opportunity costs. Gartzke et al. imply as much when they write "interdependent states can use opportunity costs as costly signals demonstrating resolve" (p 404). Put simply, this means that Gartzke et al.'s costly signaling model relies on potential trade losses associated with conflict.

Gartzke et al. claim:

"One might argue that our [Gartzke et al.'s] research design errs in light of previous studies that appear to support the opportunity costs model. How do we [Gartzke et al.] show that peace is caused by signaling? The problem is really with previous [incomplete information game theory] studies that assume (but fail to demonstrate) that a negative relationship results from opportunity costs. Rigorous theory shows that a negative relationship is the wrong hypothesis for the opportunity cost model, that opportunity costs predict no relationship." (p. 410)

Our paper illustrates that the opportunity cost model does predict such a relationship, and as a result Gartzke et al. are incorrect to claim "opportunity costs will typically fail to 
preclude militarized disputes" between interdependent states (p. 391). Indeed opportunity costs play a major role here, and in their signaling model, as well. 


\section{Appendix}

\section{Proof of Proposition 1.1.}

First, state B will accept an offer $s$ if

$$
\begin{aligned}
s & \geq(1-p) W-c_{2} \\
c_{2} & \geq(1-p) W-s
\end{aligned}
$$

and will reject it if

$$
c_{2}<(1-p) W-s
$$

Second, the expected payoff for state A with an offer $s$ given B's best response and A's belief about B's type is

$$
\begin{aligned}
\mathrm{Eu}_{1}(s \geq 0) & =(W-s) \operatorname{Pr}\left(c_{2} \geq(1-p) W-s\right)+\left(p W-c_{1}\right) \operatorname{Pr}\left(c_{2}<(1-p) W-s\right) \\
& =(W-s)(1-(1-p) W+s)+\left(p W-c_{1}\right)((1-p) W-s) .
\end{aligned}
$$

Take the first order derivative of $\operatorname{Eu}_{1}(s \geq 0)$ w.r.t. $s$ and let it equal to 0 ,

$$
\begin{gathered}
\frac{\mathrm{d}}{\mathrm{d} s} \operatorname{Eu}_{1}(s \geq 0)=-\left(1-(1-p) W+s^{*}\right)+\left(W-s^{*}\right)-\left(p W-c_{1}\right)=0 \\
-1-2 s^{*}+2(1-p) W+c_{1}=0 \\
s^{*}=\frac{-1+2(1-p) W+c_{1}}{2} .
\end{gathered}
$$

Take the second order derivative and get

$$
\frac{\mathrm{d}^{2}}{(\mathrm{~d} s)^{2}} \mathrm{Eu}_{1}(s \geq 0)=-2<0
$$

so we have a maximum. ${ }^{11}$

Third, we show this is the unique PBE to this game. To this end, we need to consider two cases in which $(1-p) W-s \leq 0$ and $(1-p) W-s \geq 1$. In the first case,

$$
\operatorname{Eu}_{1}(s \geq 0)=W-s,
$$

so the best response is to choose $\hat{s}=(1-p) W$. In the second case,

$$
\operatorname{Eu}_{1}(s \geq 0)=p W-c_{1},
$$

\footnotetext{
${ }^{11}$ Obviously, if $\left(-1+2(1-p) W+c_{1}\right)<0$, we set $s^{*}=0$.
} 
which is independent of $s$. Let $\tilde{s}=(1-p) W-1$. It is easy to check

$$
\operatorname{Eu}_{1}(\hat{s}) \geq E u_{1}(\tilde{s}) .
$$

But, since we have

$$
0 \leq(1-p) W-s^{*}=\frac{1-c_{1}}{2} \leq 1,
$$

it shows $s^{*}$ maximizes $\operatorname{Eu}_{1}(s \geq 0)$ for all $s \geq 0$ and $s^{*}$ is the unique equilibrium strategy for state $\mathrm{A}$.

\section{Proof of Proposition 2.1.}

First, state B will accept an offer $s$ if

$$
\begin{aligned}
s+b_{2} & \geq(1-p) W-c_{2} \\
c_{2} & \geq(1-p) W-s-b_{2}
\end{aligned}
$$

and will reject it if

$$
c_{2}<(1-p) W-s-b_{2} \text {. }
$$

Second, the expected payoff for state A with an offer $s$ given B's strategy and A's belief about B's type is

$$
\begin{aligned}
\mathrm{Eu}_{1}(s \geq 0) & =\left(W-s+b_{1}\right) \operatorname{Pr}\left(c_{2} \geq(1-p) W-s-b_{2}\right)+\left(p W-c_{1}\right) \operatorname{Pr}\left(c_{2}<(1-p) W-s-b_{2}\right) \\
& =\left(W-s+b_{1}\right)\left(1-(1-p) W+s+b_{2}\right)+\left(p W-c_{1}\right)\left((1-p) W-s-b_{2}\right) .
\end{aligned}
$$

Take the first order derivative of $\operatorname{Eu}_{1}(s \geq 0)$ w.r.t. $s$ and let it equal to 0 ,

$$
\begin{gathered}
\frac{\mathrm{d}}{\mathrm{d} s} \operatorname{Eu}_{1}(s \geq 0)=-\left(1-(1-p) W+s^{*}+b_{2}\right)+\left(W-s^{*}+b_{1}\right)-\left(p W-c_{1}\right)=0 \\
-1+2(1-p) W-2 s^{*}+c_{1}+b_{1}-b_{2}=0 \\
s^{*}=\frac{-1+2(1-p) W+c_{1}+b_{1}-b_{2}}{2} .
\end{gathered}
$$

Take the second order derivative and get

$$
\frac{\mathrm{d}^{2}}{(\mathrm{~d} s)^{2}} \mathrm{Eu}_{1}(s \geq 0)=-2<0
$$

so we have a maximum. ${ }^{12}$

Third, we show the equilibrium depends upon values of certain parameters. To this end,

\footnotetext{
${ }^{12}$ Once again, if $\left(-1+2(1-p) W+c_{1}+b_{1}-b_{2}\right)<0$, we set $s^{*}=0$.
} 
we need to consider two cases in which $(1-p) W-s-b_{2} \leq 0$ and $(1-p) W-s-b_{2} \geq 1$. In the first case,

$$
\operatorname{Eu}_{1}(s \geq 0)=W-s+b_{1},
$$

so the best response is to choose $\hat{s}=(1-p) W-b_{2}$. In the second case,

$$
\operatorname{Eu}_{1}(s \geq 0)=p W-c_{1},
$$

which is independent of $s$. Let $\tilde{s}=(1-p) W-b_{2}-1$. It is easy to check

$$
\operatorname{Eu}_{1}(\hat{s}) \geq E u_{1}(\tilde{s})
$$

In order for $s^{*}$ to be an equilibrium strategy, we need

$$
\begin{gathered}
0 \leq(1-p) W-s^{*}-b_{2} \leq 1 \\
0 \leq \frac{1-c_{1}-b_{1}-b_{2}}{2} \leq 1
\end{gathered}
$$

So the condition needed is

$$
1-c_{1}-b_{1}-b_{2} \geq 0
$$

since $\frac{1-c_{1}-b_{1}-b_{2}}{2} \leq 1$ is satisfied by assumption. On the other hand, if

$$
1-c_{1}-b_{1}-b_{2}<0
$$

we get equilibrium strategy $s^{*}=\hat{s}=(1-p) W-b_{2}$. 


\section{References}

[1] Barbieri, Katherine. 1996. Economic Interdependence: A Path to Peace or a Source of Interstate Conflict? Journal of Peace Research 33: 29-49.

[2] Gartzke, Erik, Quan Li, and Charles Boehmer. 2001. Investing in the Peace: Economic Interdependence and International Conflict. International Organization 55: 391-438.

[3] Gasiorowski, Mark. 1986. Economic Interdependence and International Conflict: Some Cross-Sectional Evidence. International Studies Quarterly 30: 23-38.

[4] Mansfield, Edward, and Brian Pollins. 2001. The Study of Interdependence and Conflict: Recent Advances, Open Questions, and Directions for Future Research. Journal of Conflict Resolution 45: 834-869.

[5] Martin, Philippe, Thierry Mayer, and Mathias Thoenig. 2008. Make Trade not War? Review of Economic studies Forthcoming.

[6] Morrow, James. 1999. How Could Trade Affect Conflict? Journal of Peace Research 36: $481-489$.

[7] Oneal, John R. and Bruce Russett. 1999. Assessing the Liberal Peace with Alternative Specifications: Trade Still Reduces Conflict. Journal of Peace Research 36: 423-442.

[8] Polachek, Solomon W. 1980. Conflict and Trade. Journal of Conflict Resolution 24: 55-78.

[9] Polachek, Solomon, Carlos Seiglie, and Jun Xiang. 2007. The Impact of Foreign Direct Investment on International Conflict. Defence and Peace Economics 18: 415-429.

[10] Spence, Michael. 1973. Job Market Signaling. The Quarterly Journal of Economics 87: $355-374$.

[11] Xiang, Jun, Xiaohong Xu and George Keteku. 2007. Power: The Missing Link in the Trade Conflict Relationship. Journal of Conflict Resolution 51: 646-663. 